\title{
Flucht, Vertreibung und Emigration der muslimischen Bevölkerung Bulgariens mit besonderer Berücksichtigung des Südostens (Sliven-Burgas)
}

\author{
Mehmet HacisalihoĞLU
}

Dieser Artikel behandelt die Entsiedlung der muslimischen Bevölkerung aus Bulgarien und versucht dabei die Hintergründe der muslimischen Emigration und ihre Folgen für die demographische Zusammensetzung am Beispiel der ehemaligen osmanischen Provinz Islimye (heute der südöstliche Teil Bulgariens von Nova Zagora bis Burgas) zu erklären.

Was die Geschichte des östlichen Balkanraums am stärksten charakterisiert, ist Migration. Es gab zwar in jeder Phase der Geschichte Migrationsbewegungen dieser Region, wie z.B. die slawische Landnahme, Ansiedlung der Türken usw. In der modernen Zeit haben die Migrationsbewegungen jedoch neue Dimensionen gewonnen. Diese Migrationsprozesse waren je nachdem Fluchtbewegungen, Vertreibungen, Zwangsumsiedlungen, ethnische Säuberungen, Bevölkerungsaustausch, freiwillige Auswanderung, wirtschaftliche Emigrationen bzw. Arbeitermigration oder Landflucht. Für all diese Begriffe findet man ausreichend Beispiele in Bulgarien.

Die seit dem Ende des 18. Jahrhunderts aufflammenden osmanisch-russischen Kriege sowie die Entstehung moderner Nationalstaaten im Laufe des 19. und 20. Jahrhunderts verursachten größere Bevölkerungsverschiebungen. Davon betroffen waren fast alle Gebiete der Balkanhalbinsel. Thrazien, das in der zweiten Hälfte des 19. Jahrhunderts etwa das Vilayet Edirne / Adrianopel umfasste, ${ }^{1}$ wurde zwischen drei Nationalstaaten, Bulgarien, Griechenland und der Türkei, aufgeteilt, was eine radikale Veränderung des demographischen und toponymischen Bildes dieser Region zur Folge hatte.

Diese historischen Migrationsprozesse sind bereits auf verschiedener Ebene wissenschaftlich untersucht worden. Die bisherigen Studien konzentrierten

1 Der antike Begriff Thrazien (Thrakien) wurde in der Osmanenzeit weder als eine administrative noch geographische Bezeichnung verwendet. Erst während der Entstehung der Nationalstaaten auf dem Balkan scheint der Begriff Thrazien wieder belebt worden zu sein. Die Osmanen benutzten ihn erst zu Beginn des 20. Jahrhunderts. Heute ist der Begriff sowohl in Griechenland als auch in Bulgarien und in der Türkei ein geläufiger Begriff. Bis zum osmanisch-russischen Krieg von 1877/78 umfasste die Provinz (Vilayet) Edirne (Adrianopel) ungefähr das Gebiet Thraziens. 
sich hauptsächlich auf die politischen Entwicklungen und die Beziehungen der Nachbarstaaten auf dem Balkan. Die Migration wurde dabei als ein Nebenaspekt behandelt. So entstand eine Fülle von Literatur in Bulgarien, Griechenland und der Türkei über die sogenannten „Konationalen“, die als Minderheit in Nachbarländern lebten bzw. leben. Sie liefern ein ausführliches Bild der Migrationsgeschichte der Region, da sie auf offiziellen Dokumenten, Presseberichten und Memoiren basieren. In den meisten Fällen fällt jedoch auf, dass sich jede Seite - sei es die bulgarische, griechische oder türkische - auf die eigenen „Konnationalen“ bezieht und die Forschungsergebnisse der anderen Seite meist aufgrund sprachlicher Barrieren ignoriert. Infolge dieser Tendenz entsteht eine eher einseitige Darstellung der historischen Entwicklungen, was beinahe symptomatisch für die gesamte Geschichtsschreibung auf dem Balkan ist. Häufig werden die Bevölkerungsbewegungen ganz pauschal als eine Folge der antibulgarischen, antigriechischen bzw. antitürkischen Politik erklärt. Einerseits ist dies zwar nicht von der Hand zu weisen, andererseits wird dadurch aber die Komplexität der Migrationsbewegungen übersehen, die selten auf eine einzige Ursache zurückgeführt werden können.

Diese Untersuchung basiert auf einem Forschungsprojekt über die Ortsnamen Bulgariens. ${ }^{2}$ Im Unterschied zu den bisherigen Arbeiten wurde hier versucht, die Migrationsgeschichte Bulgariens in den letzten anderthalb Jahrhunderten anhand der Entwicklung der einzelnen Dörfer zu erklären. Es wurde versucht, die komplexen Hintergründe und die Folgen von Migrationen am Beispiel von Dörfern festzustellen. Über Südost-Bulgarien vom Balkangebirge bis zur heutigen türkischen Grenze erschien bereits 2008 ein Buch auf Türkisch, in dem die Ortsnamen und die demographischen Änderungen in der Region behandelt wurden. ${ }^{3}$ Hier werden die Ergebnisse dieser Forschung zusammenfassend vorgestellt.

\section{Das untersuchte Gebiet: Das Sandschak von İslimye/Sliven}

Das nordthrazische Gebiet war eine aus acht Gerichtsbezirken (Kazas) bestehende Provinz (Sancak) mit Zentrum İslimye (Sliven) am Fuß des Balkangebirges. Sliven entwickelte sich in der Osmanenzeit aus einem Dorf des 16. Jahrhunderts

2 Zwischen 2001 und 2008 lief das Projekt Südosteuropäische Ortsnamenkonkordanz, Teil Bulgarien, in dem ich mitgearbeitet habe. Ich danke Herrn Prof. Dr. Hans Georg Majer, der das von der Deutschen Forschungsgemeinschaft finanzierte Projekt jahrelang geleitet hat, Herrn Prof. Dr. Machiel Kiel, der das Projekt betreute und sein Wissen mit mir teilte, und Herrn Fahrudin Bradarić, der mit mir im Projekt mitgearbeitet hat.

3 Hacısalihoğlu 2008. 
um die Mitte des 19. Jahrhunderts zu einer Provinzhauptstadt. Vor allem die Textil- und Waffenherstellung im 18. und 19. Jahrhundert ermöglichte diesen Aufstieg. Die erste osmanische Textilfabrik auf dem Balkan wurde 1835/36 in Sliven gegründet. Sie produzierte Kleidung für die neue osmanische Armee, die nach der Abschaffung der Janitscharenregimenter im Jahre 1826 gegründet wurde. Die Provinz Sliven war direktes Hinterland von Istanbul, und die wichtigste Verbindung der Provinz mit dem Reichszentrum war die Stadt Burgas, die sich infolge der Zunahme des Warentransports von einem Dorf zu einer bedeutenden Hafenstadt entwickelte. ${ }^{4}$

Nach dem osmanischen Provinzalmanach aus dem Jahre 1873 hatte die Provinz İslimye 444 Dörfer innerhalb von 8 Gerichtsbezirken. Rund $51 \%$ dieser Dörfer waren rein muslimisch, der Rest war muslimisch-christlich gemischt bzw. rein christlich. Die Dorfnamen waren ca. $80 \%$ türkisch (einschließlich arabisch und persisch). Der Anteil der muslimischen Bevölkerung an der Gesamtbevölkerung der Provinz lag jedoch bei ca. 46-47 \%. ${ }^{5}$

Während des osmanisch-russischen Krieges von 1877-78 wurde das Gebiet von der russischen Armee besetzt, und nach dem Berliner Kongress wurde dort die Provinz Ostrumelien gegründet. Die Provinz wurde 1885 von Bulgarien annektiert. Die Wahl dieser Region für eine Untersuchung entsiedelter Dörfer vor Ort war eine praktische Entscheidung und hatte mit der Intensität der Entsiedlungen nichts zu tun. So waren in der Provinz/Sandschak Filibe (Plovdiv) die Entsiedlungen vergleichsweise intensiver als in der Provinz Islimye. In der multiethnischen und multireligiösen Provinz Islimye (Türken, Bulgaren, Griechen, muslimische und orthodoxe Roma), die den östlichsten Teil des Balkangebirges, die thrazische Ebene und die Schwarzmeerküste umfasste, spielten sich mehrere Migrationsprozesse ab. Derart charakterisiert kann die Provinz aber doch als repräsentativ für das gesamte Bulgarien angesehen werden.

\section{Quellen und Methode}

Für diese Untersuchung wurden die Ortsnamen, die in den osmanischen Quellen und Provinzalmanachen ${ }^{6}$ nachgewiesen werden konnten, als Basis herange-

4 Hacısalihoğlu 2008, 67-80.

5 Salname Edirne 1290, 241-260. Der Umstand, dass der Anteil der Muslime an der Gesamtbevölkerung kleiner war als ihr Anteil an der Gesamtzahl der Dörfer, ist darauf zurückzuführen, dass im 19. Jahrhundert die christlichen Siedlungen in Bulgarien im allgemeinen bevölkerungsreicher waren als die muslimischen. Tendenziell waren die christlichen Haushalte durchschnittlich etwa um eine Person größer als die muslimischen Haushalte.

6 Salname Edirne 1290. 
zogen. Die festgestellten Ortsnamen wurden auf den geographischen Karten lokalisiert und identifiziert. Dabei waren die ausführlichen militärischen Karten von großer Bedeutung. Vor allem wurden die russische Heereskarte aus den 1880er Jahren ${ }^{7}$, die osmanische Heereskarte aus dem Jahre $1900^{8}$ und die österreichische Heereskarte der Jahre $1913-15^{9}$ herangezogen. Die ausgesiedelten und verschwundenen Dörfer sind auf den Heereskarten häufig als „Ruine“ markiert. Weitere Informationen über die Ortschaften wurden durch die Auswertung der bulgarischen Volkszählungen ab 1884/5 gesammelt. ${ }^{10}$ Für die administrative Entwicklung der Siedlungen und Namensänderungen waren die Ortsnamenlexika, vor allem von Petăr Koledarov und Nikolaj Mičev, sehr nützlich. ${ }^{11}$ Für die spezifischen Migrationsgründe während der russischen Militärverwaltung in der Region sind die Berichte der britischen Konsuln und Vizekonsuln sehr aufschlussreiche Quellen, da sie nicht selten über Emigrationen Dorf für Dorf berichten.

Was die schriftlichen Quellen nicht dokumentieren, sind die praktischen Folgen der Auswanderungen vor Ort. Viele Dörfer, die in der Osmanenzeit existierten, sind auf den heutigen Landkarten nicht mehr vorhanden. Um über diese Dörfer Informationen zu sammeln, wurde eine Forschungsreise in die Region unternommen mit dem Ziel vor allem die verschwundenen Dörfer mit Hilfe der GPS-Technologie ausfindig zu machen. ${ }^{12}$

Was die Strukturierung der Arbeit anbelangt, so werden zuerst die historischen Entwicklungen im 19. und 20. Jahrhundert anhand der vorhandenen Literatur zusammenfassend dargestellt. Über die politischen Entwicklungen und die Minderheitenpolitik in Bulgarien gibt es eine Reihe von Publikationen, von denen vor allem die Werke von Ali Eminov, ${ }^{13}$ Ali Dayığ $l^{14}$ und Valeri Stojanov ${ }^{15}$ zu erwähnen sind. Über die Auswanderung der Muslime aus dem Balkan infolge des osmanisch-russischen Krieges von 1877/78 ist das Werk von Nedim İpek zu von Bedeutung. ${ }^{16}$ Nach der Beschreibung der Migrationsprozesse werden einige Beispiele für entsiedelte Dörfer aus der Region der Provinz Islimye behandelt.

7 RHK, 1884.

8 OHK, 1900.

9 ÖHK, 1913.

10 Spisăk 1921.

11 Koledarov / Mičev 1989.

12 Für die Feldforschung in Bulgarien bin ich der DFG für die Finanzierung und Herrn Gürkan Riza für die Betreuung in der Region sehr dankbar.

13 Eminov 1997.

14 Dayioğlu 2005.

15 Stojanov 1998.

16 İpek 1994; Ders. 2006. 


\section{Emigration und Immigration im 19. Jahrhundert}

Im Gebiet des heutigen Bulgarien ${ }^{17}$ gab es seit dem Beginn des 19. Jahrhunderts verschiedene Arten von Migrationen, die bedeutendsten darunter wurden aufgrund der Konkurrenz zwischen den lokalen Magnaten (den sog. Ayanen) und der Zentralmacht ausgelöst. Bereits seit dem 17. Jahrhundert stärkten die Ayane ihre Machtstellung gegenüber dem Sultan. Gegen Ende des 18. Jahrhunderts rebellierte Pazvantoğlu Osman Ağa, der Ayan von Vidin, gegen den Sultan und brachte den größten Teil Bulgariens unter seine Kontrolle. ${ }^{18}$ Die militärischen Auseinandersetzungen zwischen Pazvantoğlu und der Zentralmacht verwandelten Bulgarien in einen Kriegsschauplatz und führten zu Auswanderungen. Auf der anderen Seite gab es Raubzüge der aufständischen Kircaali-Rebellen, die sich vor allem aus den Muslimen in Südbulgarien rekrutierten und fast das ganze Gebiet bis nach Rumänien mit ihren Raubzügen verunsicherten. ${ }^{19}$ Diese Verunsicherung veranlasste die muslimische und nichtmuslimische Landbevölkerung, teilweise Zuflucht in den Städten zu suchen, die für sicherer gehalten wurden als die Dörfer. Ein weiterer Teil überschritt die Donau und flüchtete in die Walachei. Der bulgarische Pfarrer Sofronij Vračanski berichtet von der Entvölkerung weiter Gebiete aufgrund dieser Rebellionen und Auseinandersetzungen. ${ }^{20}$

Ein gewichtigerer Faktor für die Auswanderungen waren jedoch die osmanisch-russischen Kriege, die vom letzten Viertel des 18. Jahrhunderts bis ins 20. Jahrhundert mehrfach ausbrachen (1768-1774, 1787-1792, 1806-1812, 1827 1829, 1853-1856, 1877-1878 und schließlich 1914-1917). Die Kriege führten zu Migrationsbewegungen der Muslime und der orthodoxen Christen. Das Gebiet des heutigen Bulgariens wurde erst im 19. Jahrhundert zum Kriegsschauplatz zwischen den beiden Imperien. Aber auch während der Kriege gegen Ende des 18. Jahrhunderts gab es Migrationsbewegungen von Orthodoxen aus der Dobrudscha (heute zwischen Rumänien und Bulgarien geteilt) ins Zarenreich. Unter den Emigranten befanden sich auch Gagauzen, türkischsprachige

17 Die Bezeichnung „Bulgarien“ wird hier für das 19. Jahrhundert von den heutigen Grenzen Bulgariens ausgehend als eine geographische Bezeichnung benutzt. In der Osmanenzeit war die Bezeichnung Bulgarien weder als administrativer noch als geographischer Name geläufig. Da viele Regionen des heutigen Bulgarien vor der Gründung des bulgarischen Staates nicht mehrheitlich bulgarisch bevölkert waren, kann der Name Bulgarien für das 19. Jahrhundert nicht im Sinne eines „bulgarischen Vaterlandes“ verwendet werden.

18 Eren 2001, 532-535.

19 Mutafćieva 1977.

20 Vraçali 2003, 48. 
Orthodoxe, die sich gegen Ende des 18. und in der ersten Hälfte des 19. Jahrhunderts teilweise in Bessarabien ansiedelten. ${ }^{21}$

Während des Krieges von 1827-29 überschritt die russische Armee das Balkangebirge, besetzte das gesamte östliche Gebiet Bulgariens und nahm schließlich Edirne / Adrianopel, die wichtigste osmanische Stadt auf dem Balkan, ein. Die russische Militärverwaltung in der Region dauerte über acht Monate, bis sich schließlich die Armeen des Zarenreiches nach dem Friedensvertrag von Edirne 1830 zurückzogen. Zahlreiche Muslime flüchteten vor den vordringenden russischen Armeen in die Reichszentrale und in andere sichere Regionen, während die orthodoxe Bevölkerung die russischen Armeen meistens mit groBer Begeisterung empfang. ${ }^{22}$ Als sich die russische Armee jedoch zurückzog, emigrierte auch eine große Zahl von orthodoxen Christen mit den Russen nach Norden. Die orthodoxen Migranten wurden vom Zaren, ausgestattet mit bestimmten Privilegien, in den neu eroberten Gebieten Russlands angesiedelt.

Die Emigration der Christen war mehr eine Folge der russischen Propaganda als die Bedrohung seitens der osmanischen Verwaltung. Die russische Armee versuchte die orthodoxe Bevölkerung zur Auswanderung zu bewegen, indem erstens mit Vergeltungen der zurückkehrenden osmanischen Verwaltung gedroht wurde und zweitens zahlreiche Versprechungen bezüglich eines besseren Lebens unter der Verwaltung des Zaren gemacht wurden. Tatsächlich wurde den christlichen Migranten in Russland Land zum Anbau gegeben, und sie wurden 20 Jahre lang von Steuern befreit. Dagegen versuchte Sultan Mahmud II. die Emigration der Nichtmuslime zu verhindern. Er lud angesehene Christen in den Palast ein und schickte sie dann mit höheren Staatsmännern in die Region. Auch der orthodoxe Patriarch von Konstantinopel schrieb mehrere Briefe an die Bevölkerung und forderte sie auf, ihre Länder nicht zu verlassen. Dennoch überschritten mehrere Zehntausende mit den russischen Soldaten die Donau. ${ }^{23}$ Aber aufgrund verschiedener Probleme bei ihrer Ansiedlung und infolge der Einladungen der osmanischen Regierung kehrte ein bedeutender Teil der christlichen Emigranten wieder in ihre Länder zurück. ${ }^{24}$ Auch während des Krimkrieges und danach gab es Auswanderungen von orthodoxen Christen aus Bulgarien nach Russland. ${ }^{25}$

Bei den russisch-osmanischen Rivalitäten handelte es sich also nicht nur um militärische Auseinandersetzungen, sondern auch um einen regen Konkurrenzkampf um die Bevölkerung. Ein bedeutender Teil der orthodoxen Untertanen

21 Radova 2006, 71-88.

22 So z.B. die Bevölkerung von Sliven und Jambol, von Moltke 1932, 206-207.

23 Tabakov 2002, 129-173.

24 Gülsoy 1993, 83-90.

25 İpek 2006, 274. 
des Osmanischen Reiches sah die Russen als Glaubensbrüder und den Zaren als Befreier an. Russland legitimierte seine Ausdehnungspolitik durch die Behauptung, es befreie die unterdrückten Christen von der türkischen Herrschaft. Die Emigration der osmanischen Christen nach Russland diente letztendlich der Bestätigung dieser Behauptung. Andererseits wollte die russische Regierung die russische Herrschaft in den neu eroberten Gebieten, vor allem auf der Krim und in Bessarabien, durch die Ansiedlung einer orthodoxen Bevölkerung stärken. Die russische Propaganda auf dem Balkan gewann um die Mitte des 19. Jahrhunderts (besonders nach dem Krimkrieg) eine neue Komponente. In den auf den Krimkrieg folgenden Jahren begann Russland eine panslawistische Propaganda auf dem Balkan, die den russischen Einfluss auf die orthodoxen Balkanslawen weiter vergrößerte. ${ }^{26}$

Auf der anderen Seite sahen die Muslime in den russisch besetzten Gebieten das Osmanische Reich als ihre Heimat an, und deswegen gab es immer wieder Wellen von Auswanderungen ins Osmanische Reich. Die Zahl der muslimischen Emigranten (muhacir) stieg infolge des russischen Eindringens in den Kaukasus in den 1860er Jahren zusehends an. Besonders nachdem der tscherkessische Widerstand gegen die russische Armee im Kaukasus im Jahre 1864 gebrochen war, begann eine Auswanderungswelle von mehreren Hunderttausenden Muslimen. Für die Ansiedlung der Emigranten wurde im Osmanischen Reich 1860 eine Migrantenkommission (muhacirin komisyonu) gegründet, und sie koordinierte in Zusammenarbeit mit der örtlichen Verwaltung die Ansiedlung der Migranten. Ein Teil der muslimischen Einwanderer wurde auf dem Gebiet des heutigen Bulgariens angesiedelt. So berichtet Nusret Pascha, der Direktor der Migrantenkommission, am 24. Juli 1864, dass sich die Zahl der Emigranten, die in den Häfen von Varna und Konstanza anlangte, auf 60.000 belief und dass diese in verschiedenen Orten auf dem Balkan angesiedelt werden sollten. ${ }^{27}$

\section{Der osmanisch-russische Krieg von 1877/78 und der Massenexodus der Muslime}

Erste massenhafte Auswanderungen der Muslime aus dem Gebiet des heutigen Bulgariens begannen während des osmanisch-russischen Krieges von 1877/78 und setzten sich in den darauf folgenden Jahren der russischen Besatzung fort. Die russischen Armeen kamen bis vor die Tore der osmanischen Hauptstadt.

26 Hacısalihoğlu 2008, 32-35.

27 BOA (Osmanisches Archiv des Ministerpräsidiums, Istanbul), A.MKT.MHM. 305/94, Datum 10 S 1281 [24.7.1864]. 
Die muslimische Bevölkerung in den russisch-besetzten Gebieten wurde Opfer von Angriffen vor allem von Kosaken-Einheiten und bulgarischen Freiwilligenverbänden. Angst vor Massakern bewegte die muslimische Bevölkerung zur massenhaften Flucht.

Die massenhafte muslimisch-türkische, griechische und jüdische Emigration hatte großen Einfluss auf die Siedlungsstruktur in Bulgarien. Eine Untersuchung der Kartenquellen dieser Zeit ergibt, dass in der südlichen Hälfte des heutigen Bulgariens 316 von insgesamt 1.942 Dörfern als Ruinen markiert sind. ${ }^{28}$

Dieselben Kartenquellen zeigen in den 444 Dörfern der Provinz İslimye/Sliven im südöstlichen Teil Bulgariens 48 Dörfer als Ruinen, wobei 25 Dörfer gar nicht erwähnt werden. Obwohl ein Teil der verlassenen Dörfer teilweise von den bulgarischen Siedlern aus Makedonien und Thrazien wiederbesiedelt wurde, blieb der Rest bis heute unbesiedelt und verschwand von den Landkarten. Jedes vierte muslimische Dorf in der Provinz wurde entweder als Ruine markiert oder gar nicht mehr auf den Karten angeführt. ${ }^{29}$ Dies ermöglicht zwar keine genauen Angaben über das gesamte Ausmaß der Auswanderung, weil auch sehr viele Siedlungen nur teilweise ausgesiedelt wurden bzw. die gemischten Siedlungen trotz der Auswanderung der Muslime, Griechen und Juden weiter existierten. Es verdeutlicht jedoch, wie radikal sich die Siedlungsstruktur des Gebietes während und infolge des Krieges von 1877/78 verändert hat.

Der Verlauf der Emigration während des Krieges stellt sich zusammenfassend folgendermaßen dar: Als die russische Armee in die Dobrudscha einmarschierte, begannen die Muslime aus der Dobrudscha zu flüchten. Dann erreichte die russische Armee Silistra, und die Muslime in der Region flüchteten zur Hafenstadt Varna, nach Şumnu (Šumen) und Osmanpazarı. Im Januar 1878 überschritt General Gurko das Balkangebirge über die Pässe Šipka und Hainboğazı, nahm die Städte Kızanlık (Kazanlăk), Eski Zağra (Stara Zagora), Yeni Zağra (Nova Zagora) und İslimye (Sliven) ein. Die Muslime der Region flüchteten vor den russischen Armeen nach Filibe (Plovdiv), von wo sie mit der Eisenbahn nach Edirne (Adrianopel) transportiert wurden. Infolge der Eroberung von Lofça (Loveč) flüchteten die Muslime nach Orhaniye (seit 1934 Botevgrad), Plevne (Pleven) und Sofia. Als Sofia 1877 eingenommen wurde, ging die Flucht in Richtung Samakov und Köstendil weiter. Von dort setzte sich die Auswanderung weiter in Richtung Skopje und Kumanovo fort. Es gibt zahlreiche Berichte über die Ermordung von Muslimen, Juden und teilweise auch von Griechen seitens

28 Hacısalihoğlu 2008, 86-88.

29 Ebd., 141-143. 
der bulgarischen Freiwilligenverbände und Kosakeneinheiten. Auch Epidemien führten zum Massentod von Emigranten. ${ }^{30}$

Die Angaben in den Memoiren aus der Zeit stimmen mit den Berichten der britischen Konsuln im Großen und Ganzen überein. ${ }^{31}$ Türkische Historiker schätzen die Zahl der Toten mit ca. 500.000 und die Zahl der Emigranten wird mit über einer Million angegeben. ${ }^{32}$

Ein Teil der Emigranten machte den Versuch in ihre Häuser zurückzukehren. Etwa 100.000 Muslime kehrten in die Provinz Ostrumelien zurück. Die Verwaltung der Provinz, die in der Hand der russischen Militärs und von Bulgaren lag, konnte bzw. wollte die Sicherheit der zurückkehrenden Muslime (sowie Griechen und Juden) nicht gewähren. Außerdem waren die Häuser der muslimischen Emigranten von der bulgarischen Bevölkerung zum Teil besetzt worden. Hinzu kommt die Bewaffnung der bulgarischen Bevölkerung durch die russische Armee und die Gründung der Gymnastikvereine (bewaffnete militärische Einheiten) in der Provinz. Die Gymnastikvereine begannen die Muslime, Griechen und Juden systematisch anzugreifen, um sie zur Auswanderung zu zwingen und die Rückkehr weiterer Emigranten zu verhindern. ${ }^{33}$ Ein wesentlicher Grund für diese Angriffe war die Furcht, dass die formell unter osmanischer Herrschaft stehende Provinz wieder unter die osmanische Zentralverwaltung geraten könnte und dass die osmanische Regierung Militär in die Provinz schicken könnte. Der russische General Obručev bekräftigte diese Ängste, indem er erklärte, dass eine Wiedereroberung des Balkans seitens der Türken von der Haltung der Bevölkerung abhinge. Dies wiegelte die bulgarische Bevölkerung gegen die Türken auf, und die Häuser von Emigranten wurden größtenteils

30 Über Ermordungen, Raub und Vergewaltigungen während des osmanisch-russischen Krieges siehe vor allem die britischen Konsularberichte, die heute im National Archives of United Kingdom (NAUK) aufbewahrt sind: Bericht des Konsuls von Adrianopel, Nr. 20, 13 Januar 1878, FO 195/1184; Bericht des Konsuls von Filibe (Plovdiv) vom 10. März 1878, FO 195/1184; über die Angriffe auf die muslimischen Flüchtlinge, die nach dem Krieg in ihre Dörfer zurückkehren wollten, Bericht des Konsuls von Adrianopel, Nr. 74, 19. November 1878, FO 95/1185; über die Krankheiten in Filibe (Plovdiv), Bericht des Konsuls von Filibe (Plovdiv), Nr. 14, 3. Mai 1878, FO 195/1184. Über die Angriffe auf die Juden in Kizanlik s. z.B. Bericht des britischen Konsuls von Edirne, Nr. 15, 9. Januar 1878, und seine Beilage „Mr. Lowy to the Earl of Derby, Anglo-Jewish Association, Secretary`s Office, London: Extract form the "Jewish Chronicle“ of October 5, 1877, Horrible Atrocities upon the Jews of Bulgaria“, FO 195/1184. Siehe außerdem: İpek 1994, 5, 11, 24-26; Şimşir 1989; Eminov 1997, 48; Kerman 1987.

31 Hüseyin Raci Efendi.

32 İpek 1994, 40; Ders. 2006, 97.

33 Ipek 1994, 126-128; Aydin 1992, 27-32, 235-236; als Beispiel für die Angriffe siehe außerdem ein Beschwerdeschreiben von Dorfvorstehern von Aydos (Aytos), National Archives of United Kingdom, FO 195/1252. 
zerstört, um ihre Rückkehr zu verhindern. ${ }^{34}$ Auf der anderen Seite emigrierten viele Bulgaren aus dem osmanischen Gebiet nach Ostrumelien und Bulgarien. ${ }^{35}$

Die Emigration der bulgarischen Muslime ging auch nach der Annexion Ostrumeliens seitens Bulgariens weiter. Es gibt mehrere Gründe für die Abwanderung der Muslime. Einer der Gründe war z.B. die Einführung des Militärdienstes für Muslime, aber auch die Zerstörung religiöser Stiftungen, die Konfiszierung von Eigentum und ähnliches trug dazu bei, die Emigration zu beschleunigen. ${ }^{36}$

\section{Beispiele für verschwundene Dörfer}

Die hier behandelten Beispiele für ausgesiedelte und verschwundene Dörfer stammen aus der Region des ehemaligen Sandschaks İslimye (Sliven).

Eines während dieser Zeit verschwundenen Dörfer ist das Dorf Lopaçlar in der Kaza Misivri: Lopaçlar befindet sich im Balkangebirge $24 \mathrm{~km}$ entfernt von Misivri (heute Nesebăr). Es war ein eher kleineres muslimisches Dorf. ${ }^{37}$ Nach 1878 begann die Emigration der Bevölkerung aus dem Dorf. In der bulgarischen Volkszählung von 1887 gab es dort noch 34 Einwohner, ${ }^{38}$ zwei Jahre später wurde das Dorf ausgesiedelt. ${ }^{39}$ In der österreichischen Heereskarte erscheint es als Ruine. ${ }^{40}$ Nach einer Koordinatenrechnung auf der Grundlage der österreichischen Heereskarte und mit Hilfe eines GPS-Gerätes ließ sich die geographische Lage des Dorfes feststellen. ${ }^{41}$

34 Die Berichte des britischen Vizekonsuls von Burgas, Nr. 15, 14. April 1879; Nr. 16, 22. April 1879; Nr. 39, 30. September 1879, FO 195/1252; der Bericht des britischen Konsuls von Filibe (Plovdiv), Nr. 171, 24. Juni 1879, FO 195/1253, National Archives of United Kingdom.

35 Mitev 1980, 19.

36 İpek 1994, 130-149; Kocacik 1980, 137-190; Für die Vernichtung der muslimischen Stiftungen s. Ersoy 1996.

37 Nach den 1844-45 erstellten osmanischen Eigentumsregistern gab es in dem Dorf 15 muslimische Haushalte. BOA, ML.VRD.TMT. 6134, tarih 1260-61.

38 Spisăk, 1921, 304.

39 Mičev / Koledarov 1989.

40 OHK 45/43.

41 Der Name des Ortes ist den Hirten in der näheren Umgebung bekannt. Die Koordinaten von Lopaçlar $42^{\circ} 49^{\prime} 00 \mathrm{~N}$ und $27^{\circ} 32^{\prime} 20 \mathrm{O}$; die muslimische Grabstätte 42 49'00,9 N und $27^{\circ} 32$ ' $13,9 \mathrm{O}$. 


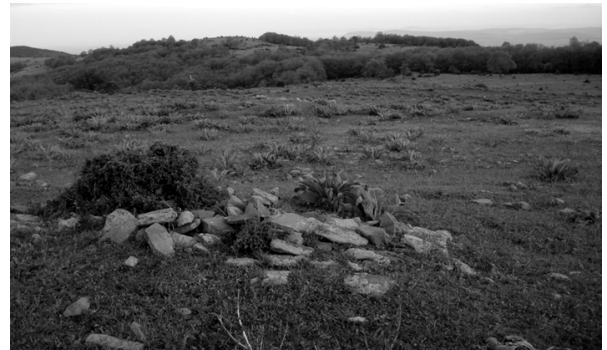

Abb. 1: Foto Hac1salihoğlu.

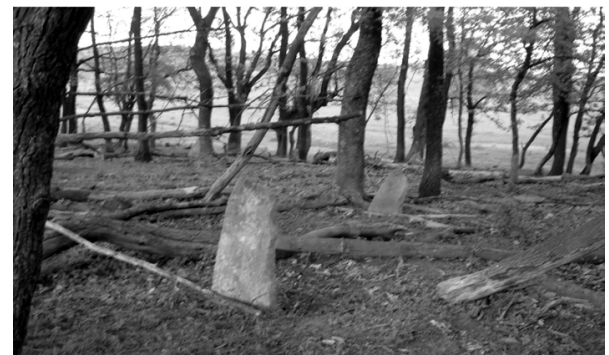

Abb. 2: Foto Hacisalihoğlu.

Wie aus den Bildern ersichtlich, sind Reste von Häusern noch erkennbar. Der Friedhof des Dorfes ist ebenfalls noch erkennbar. Es gibt noch stehende Grabsteine und viele, die auf dem Boden liegen. Alle diese Grabsteine haben jedoch keine Inschriften. Die Wasserquelle des Dorfes wurde und wird möglicherweise noch von Hirten benutzt.

Ein weiteres muslimisches Dorf mit einem ähnlichen Schicksal ist Gedikler in der Kaza Misivri. ${ }^{42}$ Das Dorf befindet sich ebenfalls im Balkangebirge. Noch 1885 wurden dort 131 Einwohner gezählt. ${ }^{43}$ Nach 1892 wurde es ausgesiedelt. ${ }^{44}$ Nur mit Hilfe von Hirten in der Umgebung ließ sich das verschwundene Dorf finden. Das Dorf bestand aus Ober- und Untervierteln (yukarı ve aşağı mahalle).

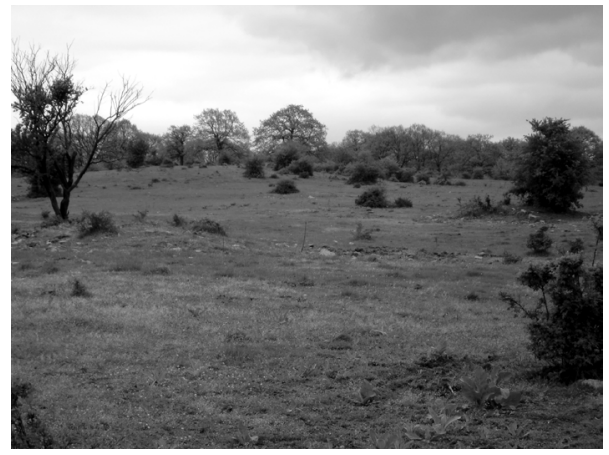

Abb. 3: Foto Hac1salihoğlu.

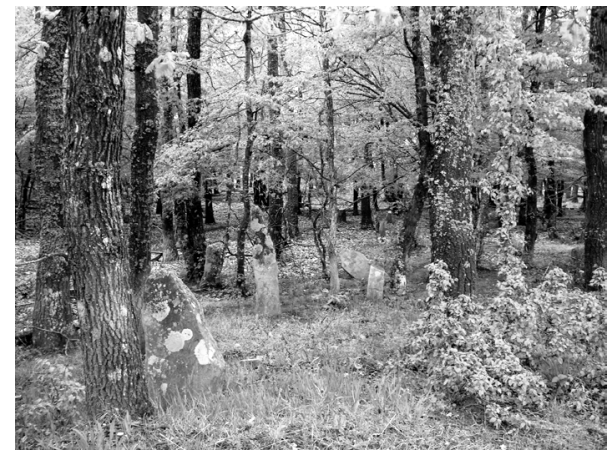

Abb. 4: Foto Hac1salihoğlu.

42 Nach den 1844-45 erstellten Eigentumsregistern gab es in dem Dorf 10 muslimische Haushalte. BOA, ML.VRD.TMT. 6163, tarih 1260.

43 Spisăk, 1921, 247.

44 Mičev / Koledarov 1989. 


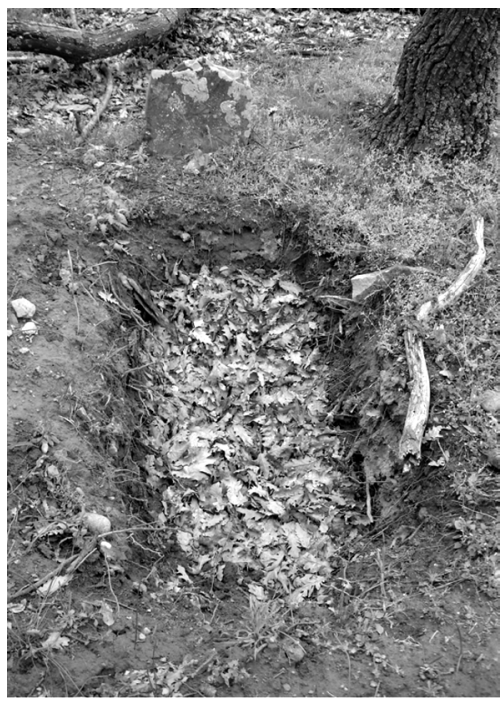

Abb. 5: Foto Hacısalihoğlu.

Anhand der herumliegenden Steine und von Hausresten kann man Häuser des Dorfes klar lokalisieren. Auch eine Wasserquelle des Dorfes findet sich noch, sie wird von Hirten benutzt. Der Friedhof des Dorfes liegt etwa einen Kilometer östlich. Zahlreiche Grabsteine sind dort noch sichtbar.

Diese beiden Dörfer haben eine Gemeinsamkeit: Beide befinden sich im Balkangebirge und die Spuren, die man ca. 130 Jahre nach ihrer Entsiedlung heute noch sieht, verdankt man ihrer geographischen Lage als Bergdörfer. Sie wurden weder wiederbesiedelt noch wurde dort Ackerbau betrieben. Da die Dörfer schwer erreichbar waren, hat man die Haussteine auch nicht weggeschleppt. Bisher wurden diese Dörfer nur von Hirten besucht, in der letzten Zeit aber offenbar auch von Schatzgräbern, denn einige der Gräber wurden aufgegraben.

Mehrere Dörfer, die infolge des Krieges von 1877/78 ausgesiedelt wurden, befinden sich dagegen in den leicht erreichbaren Ebenen, wurden unter den Pflug genommen und werden heute als Äcker verwendet. Von solchen Dörfern sind so gut wie keine Spuren erhalten geblieben. Nur ihre Namen sind teilweise als Ortsnamen noch unter der Bevölkerung bekannt.

Für solche Dörfer gibt es zahlreiche Beispiele. Das Dorf Kasapli in der Kaza Yanbolu (heute Jambol) war nach osmanischen Dokumenten aus dem 16. Jahrhundert ein Dorf der mulimischen Yürüken. ${ }^{45}$ Die muslimische Bevölke-

45 Gökbilgin 1957, 162. 
rung begann das Dorf nach 1878 zu verlassen. 1889 wurden dort 60 Einwohner gezählt; kurz darauf wurde es ausgesiedelt. ${ }^{46}$

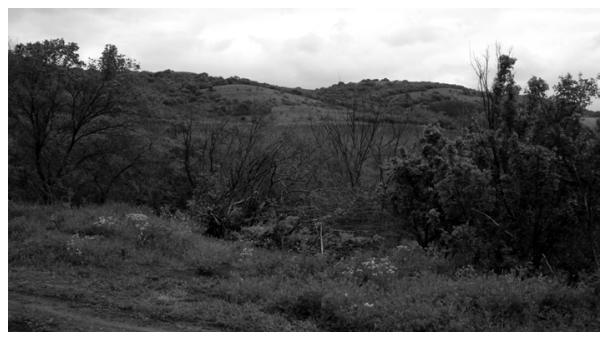

Abb. 6: Foto Hacisalihoğlu.

Als wir die Stelle des Dorfes fanden, sahen wir nur ein Feld, das mit Maschinen bestellt wurde. ${ }^{47}$ Es gab keine erkennbaren Spuren des Dorfes. Ein ca. 70 jähriger Einwohner eines benachbarten Dorfes erzählte uns, dass in seiner Kindheit noch Hausreste und Grabsteine zu sehen waren. Erst nach der Bearbeitung des Feldes mit Maschinen seien alle Spuren verloren gegangen.

Wie bereits erwähnt, führte der Krieg von 1877/78 in Bulgarien auch zur Auswanderung von Griechen. Vor allem in der Schwarzmeer-Region machte die griechische Bevölkerung einen großen Teil der Bevölkerung aus. Es gibt zahlreiche Hinweise darauf, dass auch die Griechen von der bulgarischen Verwaltung und den Milizen in der Provinz Ostrumelien angegriffen und zur Emigration gezwungen wurden. Der britische Vizekonsul von Burgas berichtet im Mai 1879, dass der Vizegoverneur von Ahyolu (Anhialo) und Misivri (Mesemvria) aus den bulgarischen Dorfbewohnern bewaffnete Verbände bildete und mit diesen Verbänden, unter dem Vorwand, für die Milizen Soldaten zu rekrutieren, die griechischen Dörfer und Städte angriff. Demnach führte dies zur Auswanderung zahlreicher Griechen aus der Region. ${ }^{48}$ Ein Beispiel für die verschwundenen griechischen Dörfer ist Iraklion (Türkisch: Ereğli) in der Kaza Misivri. Nach dem osmanischen Vilayetsalmanach von 1873 zahlte das Dorf jährlich 1.050 Kuruş Militärersatzsteuer. ${ }^{49}$

46 Spisăk, 1921, 242; Mičev / Koledarov 1989.

47 Die Stelle konnten wir mit Hilfe eines GPS-Gerätes finden.

48 Der Bericht des britischen Vizekonsuls von Burgas, Nr. 17, 8. Mai 1879, NAUK, FO 195/1252. Der Bericht enthält auch mehrere Beschwerdeschreiben von Griechen aus den Dörfern Emine und Bani in der Kaza Misivri (Mesemvria).

49 Mit der Abschaffung der Kopfsteuer (Cizye) im Jahre 1855 wurde auch Militärdienst für die Nichtmuslime eingeführt. Allerdings blieb diese Entscheidung auf dem Papier und die Nichtmuslime kauften sich durch die Militärersatzsteuer vom Militärdienst frei. Die Summe der Steuer entsprach ungefähr der Summe der früheren Kopfsteuer. Die Angabe der Militärersatzsteuer im osmanischen Almanach von Edirne aus 1873 deutet 


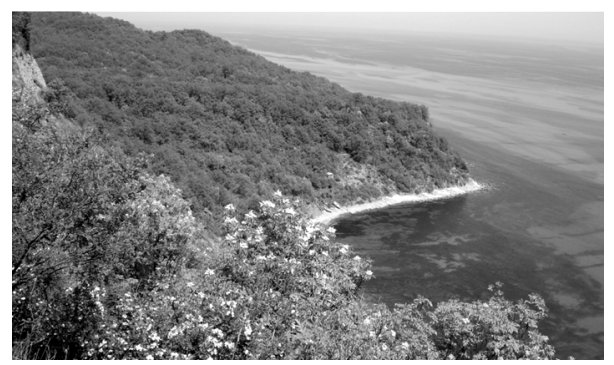

Abb. 7: Foto Hacısalihoğlu.

An der Stelle des Dorfes am Schwarzen Meer konnte ich keine Spuren von einer früheren Siedlung finden. Das ganze Gebiet wurde mit Maschinen bearbeitet und bewaldet. Der Name des Dorfes existiert jedoch als „Irakli“ weiter und aufgrund seiner steilen Lage zum Meer wird der Ort von Jugendlichen als Camping-Platz benutzt.

Nicht alle spurlos verschwundenen Dörfer sind heute jedoch Ackerfelder oder Wälder geworden. Ein tscherkessisches Dorf mit dem Namen Eğriboyun (in der Kaza Karinabad/Karnobat), das vermutlich infolge der tscherkessischen Emigration ins Osmanische Reich um die Mitte des 19. Jahrhunderts entstand, wurde 1878 ausgesiedelt. ${ }^{50}$ Heute befindet sich an seiner Stelle ein Stausee, der im 20. Jahrhundert gebaut wurde.

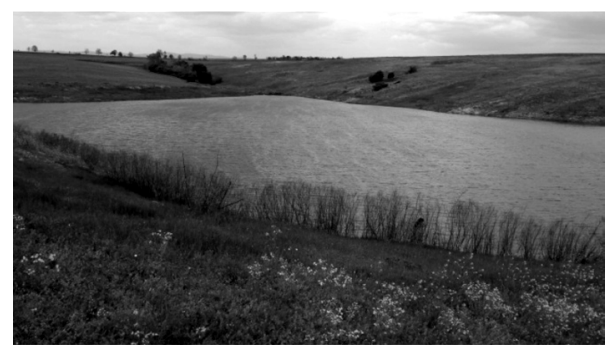

Abb. 8: Foto Hacisalihoğlu.

Viele muslimische Dörfer, die infolge des Krieges von 1877/78 verlassen wurden, wurden von bulgarischen Emigranten (teilweise aus dem südlichen Teil Thraziens (heute türkisch und griechisch) und aus Mazedonien wiederbesiedelt.

auf die Existenz einer nichtmuslimischen Bevölkerung in den Dörfern. Für die Militärersatzsteuer s. Gülsoy 2000; Heinzelmann 2004; Zürcher 1998, 437-449; Hacısalihoğlu 2007b, 264-286.

50 Salname Edirne 1290; RHK VI/8: Čerkeskioy razv. Bei Mičev / Koledarov nicht erwähnt. 
Einige dieser Dörfer sind sogar zu Städten gewachsen. Ein Beispiel für solche Dörfer bildet Cimoz (in der Kaza Misivri). Nach den osmanischen Eigentumsregistern hatte das Dorf im Jahre 1844/45 8 muslimische Haushalte (davon 3 muslimisch-zigeunerisch). In der russischen Heereskarte (RHK) wird das Dorf als Ruine erwähnt: Razv. Čimus. Bis 1892 blieb das Dorf ausgesiedelt. Erst in diesem Jahr wurden im Dorf 67 Griechen und 8 Türken gezählt. In der Volkszählung von 1900 wurden im Dorf 7 Bulgaren und 71 Griechen und im Jahre 191038 Bulgaren, 114 Griechen und 2 Türken gezählt. 1934 wurde der Name des Dorfes als Čimovo bulgarisiert. Mit der Umbenennung zu Aheloj im Jahre 1960 wurde die Bulgarisierung des Namens vollendet. 1987 lebten im Dorf 2.052 Einwohner. ${ }^{51}$

Ein weiteres Dorf, das nach 1878 verlassen wurde, war Gürgen (in der Kaza Misivri). 1844/45 wurden im Dorf 17 muslimische Haushalte gezählt. ${ }^{52}$ Die muslimischen Einwohner emigrierten in den auf den Krieg von 1877/78 folgenden Jahren aus dem Dorf. 1884 zählte man dort noch 179 Türken und 4 Bulgaren. 1910 sank die Zahl der Türken auf 21 und die Zahl der Bulgaren stieg auf 157. ${ }^{53}$ Die im Dorf gezählten Bulgaren waren wahrscheinlich meistens bulgarische Emigranten aus dem osmanischen Teil Thraziens. ${ }^{54}$ Nach Mičev / Koledarov wurde das Dorf 1912 ausgesiedelt und nach dem Ersten Weltkrieg wiederbesiedelt. ${ }^{55}$

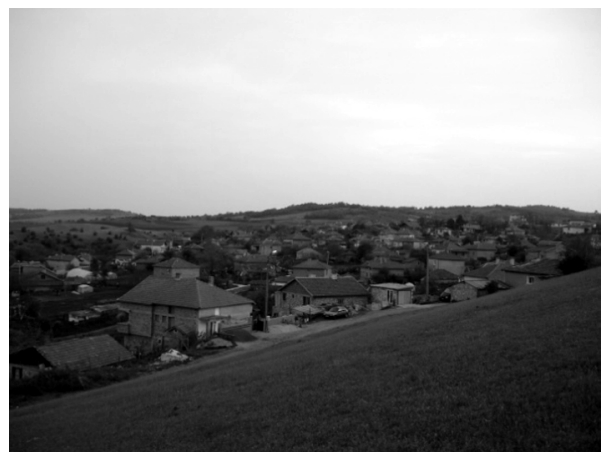

Abb. 9: Foto Hac1salihoğlu.

51 BOA, ML.VRD.TMT. 6152, tarih 1260; Spisăk, 1921, 528; Mičev / Koledarov 1989.

52 BOA, ML.VRD.TMT. 6136, tarih 1260-61.

53 Spisăk, 1921, 131.

54 Die bulgarischen Migranten wurden als „bežanci“ und / oder „maçuri“ bezeichnet. Das zweite Wort ist eine bulgarisierte Form des türkischen Wortes Muhacir, eine Bezeichnung für die zur Auswanderung gezwungene muslimische Bevölkerung.

55 Mičev / Koledarov 1989. 
Im Rahmen der Bulgarisierung der nichtbulgarischen geographischen Bezeichnungen wurde der Name des Dorfes 1931 zu Gabrevo geändert und 1966 zu Gaberovo korrigiert. Damit wurde die Bulgarisierung des Dorfes vollendet. Nach der Verstaatlichung des privaten Eigentums in der sozialistischen Zeit begann jedoch eine neue Welle der Emigration. Die Einwohner des Dorfes, deren Grundstücke und Güter verstaatlicht wurden, wanderten in die Küstenstädte am Schwarzen Meer. An ihre Stelle kamen in den 1950er und 1960er Jahren die Einwohner der im Balkangebirge noch erhaltenen muslimischen Dörfer, die ebenfalls nach der Verstaatlichung ihrer Güter ihre Bergdörfer verlassen mussten. Infolge dieses Prozesses wurde das Dorf wieder zu einem muslimisch-türkischen Dorf (wie die Einwohner es selber bezeichnen ,rein türkisch“ [,temiz Türk“] aus dem Bulgarischen „čisto turski“ übersetzt). Heute leben dort ca. 400-500 Menschen. Das Dorf Gürgen (Gaberovo) zeigt deutlich die Komplexität von Migrationsprozessen in der Region.

\section{Ortsnamenspolitik und Emigration in der ersten Hälfte des}

\section{Jahrhunderts}

Die Auswanderung der Muslime aus Bulgarien begann mit der Gründung des bulgarischen Staates und dauert bis zur Gegenwart an, was eine Folge der bulgarischen Minderheitenpolitik ist. Die bulgarische Regierung versuchte die Spuren der osmanischen Herrschaft durch verschiedene Maßnahmen zu beseitigen. So wurden z.B. die muslimischen Stiftungen von der bulgarischen Regierung konfisziert. ${ }^{56}$ Eine weitere Maßnahme war die Bulgarisierung von Ortsnamen, um ein sprachlich homogenes bulgarisches Land zu schaffen. ${ }^{57}$ Am 21. Dezember 1906 beschloss die bulgarische Regierung unter Ministerpräsident Dimităr Petkov die Ortsnamen zu ändern. Mehrere Hundert Dörfer wurden im Rahmen dieses Beschlusses umbenannt. ${ }^{58}$

Nach der Annexion Ostrumeliens im Jahre 1885 war die bulgarische Regierung bestrebt, die Grenzen von San-Stefano zu verwirklichen. Gemäß der bulgarischen Propaganda sollten Mazedonien und Thrazien, die zum Osmanischen Reich gehörten, dem bulgarischen Nationalstaat einverleibt werden, weil die Mehrheit der Bevölkerung in diesen Gebieten bulgarisch sei. Diesem Bestre-

56 Dazu s. Ersoy 1996; Ersoy 2009, 155-176.

57 Ähnliche Homogenisierungsmaßnahmen wurden auch in anderen Balkanländern, wie z.B. in Griechenland und in der Türkei, getroffen. Daher ist diese Politik Bulgariens kein Einzelfall auf dem Balkan. Dasselbe gilt auch für die Minderheitenpolitik.

58 Zur Ortsnamenpolitik Bulgariens s. Mičev / Koledarov 1989; Hacısalihoğlu 2007a; Ders. 2006; Ders. 2008. 
ben, das durch die Organisierung illegaler Komitees innerhalb des osmanischen Territoriums realisiert werden sollte, widersetzte sich die osmanische Regierung durch Reformen und militärische Bekämpfung der illegalen Komitees besonders ab 1902. Die Aktivitäten der bulgarisch-mazedonischen illegalen Komitees in Mazedonien provozierten auch den Widerstand der Griechen und Serben. So erlebte die Mazedonische Frage ihre höchste Phase zwischen 1902-1908. ${ }^{59}$ Die osmanischen Oppositionellen, die Jungtürken, setzten sich im Jahre 1908 mit der ,jungtürkischen Revolution“ gegen den Sultan durch. Die jungtürkische Regierung versuchte, Mazedonien unter Kontrolle zu bringen, was ein Bündnis der verfeindeten Balkanstaaten Bulgarien, Griechenland, Serbien und Montenegro provozierte. ${ }^{60}$ 1912/13 wurde der Balkan zum Schauplatz eines blutigen Krieges zwischen dem Osmanischen Reich und den vereinigten Balkanstaaten. Die Eroberung osmanischen Gebietes bis hin zum Vorort von Istanbul hatte auch Folgen für die muslimische Bevölkerung. Nach den Angaben türkischer Historiker schätzt man die Zahl der Toten auf ca. 200.000. ${ }^{61}$ Im Zweiten Balkankrieg konnte das Osmanische Reich die Stadt Edirne, die von der bulgarischen Armee eingenommen worden war, zurückerobern. Während und infolge der Balkankriege ging die Auswanderung in mehrere Richtungen. Muslime in den griechisch, serbisch bzw. bulgarisch besetzten Territorien wanderten ins Osmanische Reich; Griechen in Ostthrazien unter osmanischer Verwaltung und in Bulgarien emigrierten nach Griechenland und Bulgaren in Ostthrazien wurden zur Auswanderung nach Bulgarien gezwungen. Es gab verschiedene Vereinbarungen über Bevölkerungsaustausch zwischen Bulgarien, dem Osmanischen Reich und Griechenland, die teilweise auch in die Tat umgesetzt wurden. ${ }^{62}$

Während und infolge des Ersten Weltkrieges lassen sich ebenfalls Migrationsprozesse feststellen. Während die muslimische Bevölkerung in den von der russischen Armee besetzten Gebieten zur Auswanderung gezwungen wurde, wurden die armenischen Untertanen des Osmanischen Reiches zwangsweise umgesiedelt, mit schweren Folgen für die armenische Bevölkerung. Nach dem Ersten Weltkrieg und vor allem infolge des griechisch-türkischen Krieges in Westanatolien wurde zwischen Griechenland und der Türkei ein Vertrag über Bevölkerungsaustausch geschlossen, nach dem über eine Million Orthodoxe aus der Türkei gegen mehrere Hunderttausend Muslime aus Griechenland

59 Adanir 1979.

60 Hacısalihoğlu 2003.

61 Şimşir 1992, 52f; A ğanoğlu 2001, 69; Halaçoğlu 1994, $29 f f$.

62 Bericht des britischen Konsuls von Adrianopel, 31 Dezember 1913, 1-5; A ğanoğlu 2001, 120-123; Önder 1991, 207-225. 
ausgetauscht wurden. ${ }^{63}$ Während dieser Entwicklungen blieben die türkischbulgarischen Beziehungen relativ stabil.

1923 wurde die Regierung unter Stambolijski mit einem Militärputsch gestürzt und in der Zeit der neuen Regierung begann sich die Lage für die muslimische Minderheit in Bulgarien zu verschlechtern. Besonders im Jahre 1934, in dem ein Militärputsch eine nationalistische Regierung unter Kimon Georgiev an die Macht brachte, begann die neue Regierung Parolen wie „Nationale Einheit" in Vordergrund zu stellen. In dieser Zeit wurden viele türkische Schulen und Zeitungen geschlossen, und auf die türkische Minderheit wurde Druck ausgeübt, das Land zu verlassen. Als Folge dieser verschärften Situation wurden zwischen der türkischen und bulgarischen Regierung Vereinbarungen bezüglich der Emigration der Türken in die Türkei geschlossen. Zwischen 1934 und 1938 sind ca. 73.000 Menschen in die Türkei ausgewandert; 1939 stieg die Zahl insgesamt auf 95.494. Allerdings verlief dieser Prozess nicht ohne Ausbrüche von Gewalt, so wurden zahlreiche türkische Intellektuelle getötet. ${ }^{64}$

Eine weitere wichtige Entwicklung im Jahre 1934 war die Bulgarisierung der Ortsnamen, die im Prozess der Ortsnamensänderungen im Jahre 1906 nicht verändert worden waren. Im August und Dezember 1934 wurde beschlossen, die nichtbulgarischen Namen von Orten zu ändern. Dadurch fand die umfangreichste Ortsnamensänderung in Bulgarien statt, in deren Folge ca. 1971 Orte umbenannt wurden. ${ }^{65}$

Es gibt in der untersuchten Region einige während dieser Welle der Emigration ausgesiedelte Dörfer. Eines dieser Dörfer war Sarhanlar/Saruhanlar (in der Kaza Aydos). Sarhanlar war 1844/45 ein muslimisches Dorf mit 13 Haushalten. ${ }^{66}$ In der Volkszählung von 1884 wurden dort 137 Türken gezählt. 1910 stieg ihre Zahl auf 215. Der Name des Dorfes wurde 1934 zu Žăltichan geändert. 1937 wurde das Dorf verlassen und aus dem Register gelöscht. Während der Untersuchung in der Region konnte ich einen bulgarischen Augenzeugen im nahegelegenen Dorf Topolica (früher: Kavak Mahalle) finden, der die Einwohner dieses Dorfes bei ihrer Abreise mit Karren gesehen hat. Ich konnte das Dorf nicht erreichen, aber es sollen von diesem Bergdorf noch einige Spuren wie Grabsteine und Hausreste erhalten sein.

63 Ari 1995; Pentzopoulos 2002.

64 Stojanov 1998, 87-91; Eminov 1997, 49.

65 Mičev / Koledarov 1989, 10.

66 BOA, ML.VRD.TMT. 11836, tarih 1260-61; Spisăk, 1921, 423; Mičev / Koledarov 1989. 


\section{Auswanderungen in der Zweiten Hälfte des 20. Jahrhunderts}

Bulgarien ging aus dem Zweiten Weltkrieg als Verlierer hervor. Die Rote Armee marschierte in das Land ein und führte einen Regierungswechsel herbei. Die neue bulgarische Regierung richtete sich nach Moskau aus, und Bulgarien wurde zu einem sozialistischen Land. Bis 1947 festigte sich das sozialistische System und die Kommunistische Partei Bulgariens begann eine stalinistische Politik zu verfolgen. Während der Spannungen zwischen dem Ostblock und dem Westen, wobei die Türkei hatte sich durch die Nato-Mitgliedschaft für den Westen entschieden hatte, begann in Bulgarien der Druck auf die Türken zu wachsen. Ein wichtiger Grund für die Bereitschaft der Türken Bulgarien zu verlassen, war die Kollektivisierung der Landwirtschaft, die Trudovo Kooperativno Zemedelsko Stopanstvo (TKZS), also „Arbeitsgenossenschaftliche Agrarwirtschaft“ genannt wurde. Die Kollektivisierung begann im Jahre 1947, und bis 1958 wurden 92 \% des anbaufähigen Landes verstaatlicht. Hinzu kamen die Verbote bezüglich des kulturellen und religiösen Lebens der Muslime unter der sozialistischen Regierung. In den TKZS waren die Türken außerdem meistens in einem den Bulgaren untergeordneten Verhältnis. Auch die Sowjetunion unter Stalin bewilligte die Auswanderung der Türken. Daraufhin wurde 1950 zwischen der Türkei und Bulgarien eine Vereinbarung geschlossen, die vorsah, dass ein Teil der Türken in die Türkei auswandert. Bis zur Schließung der Grenzen 1952 bellief sich die Zahl der Ausgewanderten auf insgesamt 162.000. ${ }^{67}$

Eines der Dörfer, das im Jahre 1951 verlassen wurde, war Cuma Köy (in der Kaza Ahyolu). 1884 wurden im Dorf 77 Türken gezählt, deren Zahl im Jahre 1910 auf 154 stieg. Der Name des Dorfes wurde 1934 als Sborsko bulgarisiert. ${ }^{68}$

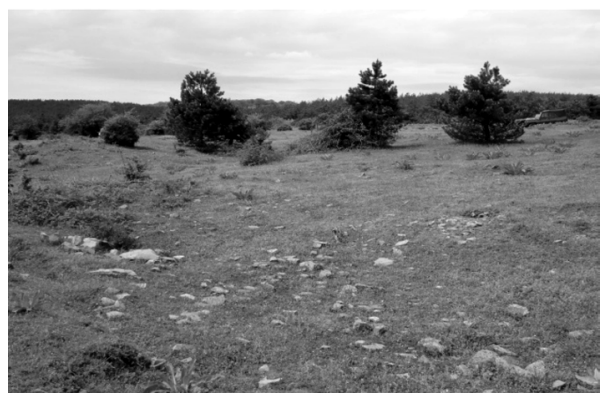

Abb. 10: Foto Hacisalihoğlu.

67 Crampton 2007, 190f; Dayioğlu 2005, 359-363.

68 Spisăk, 1921, 146 
Heute kann man an der Stelle des Dorfes noch Haussteine sehen. Die sich in der Gegend bewegenden Hirten erzählten uns ausführlich über das Schicksal des Dorfes, wo sich einmal die Moschee befand etc.

Ein anderes muslimisches Dorf namens Celepköprü (in der Kaza Aydos), das 1952 verlassen wurde, wurde von Bulgaren wiederbesiedelt. Aber auch die Bulgaren verließen dieses Dorf in den 1970er Jahren. Heute befinden sich dort nur 4 Haushalte.

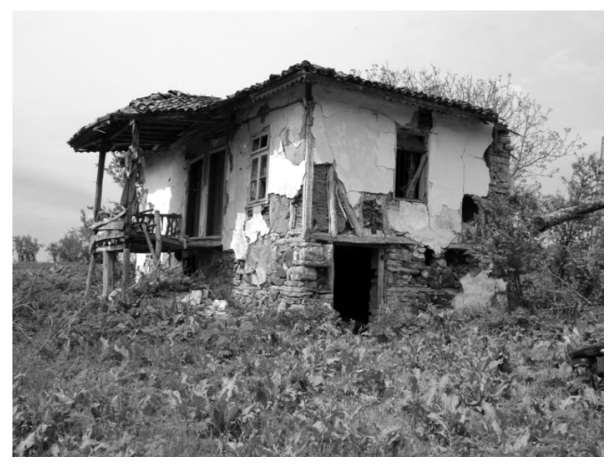

Abb. 11: Foto Hac1salihoğlu.

Die sozialistische Zeit war nicht nur durch die Emigration der Türken in die Türkei, sondern auch durch eine innere Migration in Bulgarien charakterisiert. Einer der wichtigsten Gründe für die innere Migration in Bulgarien war die sozialistische Agrarpolitik. Durch die TKZS-Politik nach dem sowjetischen Beispiel der Kolhoz wurde die Landbevölkerung gezwungen, unter staatlicher Aufsicht in den Feldern zu arbeiten. Die Bevölkerung in den für die Agrarwirtschaft ungeeigneten Dörfern wurde zur Auswanderung in die landwirtschaftlichen Dörfer gezwungen. Diejenigen, die sich weigerten, wurden durch verschiedene Zwangsmaßnahmen wie Festnahme, Prügel etc. zur Auswanderung gezwungen. Infolge dieser Politik wurden zahlreiche Bergdörfer ausgesiedelt. Eines dieser Dörfer war Denizler in der Kaza Misivri, ursprünglich ein muslimisches Dorf, in dem 1885 noch 190 Einwohner lebten. Nach der Auswanderung der Türken wurde das Dorf von Bulgaren wiederbesiedelt und ihre Zahl stieg 1910 auf 270 Einwohner. ${ }^{69}$ Die Moschee und die Schule des Dorfes wurden in eine Kirche umgewandelt. Der Name des Dorfes wurde als Morsko bulgarisiert, indem er ins Bulgarische übersetzt wurde. Aufgrund der TKZS-Politik wurde das Dorf in den 1950er und 1960er Jahren völlig ausgesiedelt. Heute lebt dort ein Hirte mit seinem Vater. Seine Frau und Kinder leben in einem anderen Dorf.

69 Spisăk, 1921; Ersoy 1996, 118. 


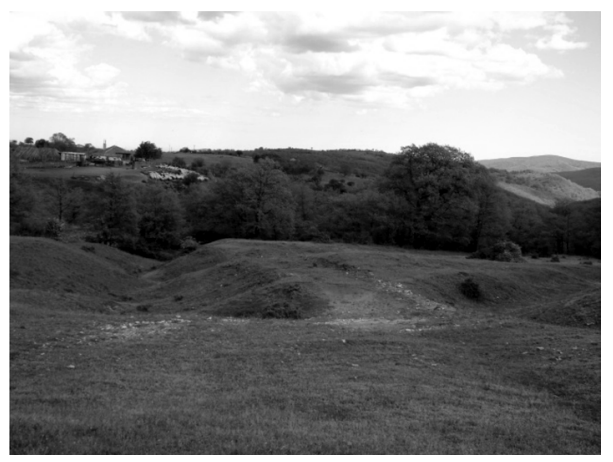

Abb. 12: Foto Hacisalihoğlu.

Ein ähnliches Schicksal hatten die Bergdörfer Kayrak (1934 Plazovec), Veli Beșe (1934 Velikovo), Kemhalık (1934 Božur) und Kalgamaç (1934 Dobrovan) in derselben Region. ${ }^{70}$

Ein weiterer Grund für die Auswanderungen war der Bau von Stauseen in der Zeit des Sozialismus. Vor allem in den 1970er Jahren wurden im untersuchten Gebiet zwei große Stauseen, Conevo und Žrepčevo, angelegt, weshalb 4 muslimische und 2 bulgarische Dörfer ausgesiedelt wurden.

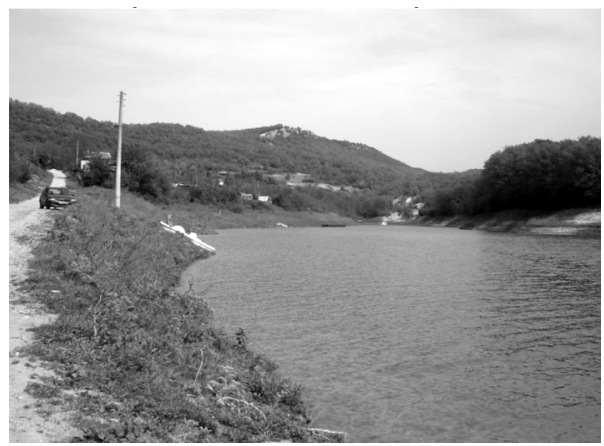

Abb. 13: Foto Hacısalihoğlu.

Drei muslimische Dörfer am Fluss Kamçı/Kamčija innerhalb des Distrikts Aytos, Kara Ahmed Mahalle, Deli Hüseyin Mahalle und Kısıklar Emir Mahalle, wurden wegen des Baus des Stausees Conevo in den 1970er Jahren ausgesiedelt. Der untere Teil von Kara Ahmed Mahalle blieb unter Wasser, die Deli Hüseyin Mahalle wurde gänzlich geflutet. Auch wenn der Wasserstand weiter steigt, ist die Kisıklar Emir Mahalle noch nicht unter Wasser. Dort wird Landwirtschaft

70 Hacısalihoğlu 2008, 100-103. 
betrieben. Außer den Ruinen einer Brücke sind keine Spuren des Dorfes erhalten geblieben, obwohl es erst vor 35-40 Jahren ausgesiedelt wurde. Alle Hausbausteine wurden weggeschleppt.

Die Minderheitenpolitik Bulgariens begann in der sozialistischen Zeit repressiver zu werden. Um die Mitte der 1950er Jahre wurden die Namen der muslimischen Pomaken zwangsweise bulgarisiert. Obwohl in den 1960er Jahren den Pomaken wieder erlaubt wurde, ihre muslimischen Namen zu führen, beschloss das Politbüro 1970 erneut die Namen zu ändern. Zwischen 1971 und 1973 wurden die Namen der Pomaken durch bulgarische Namen ersetzt. Im selben Jahr wurden zudem die Schulen mit türkischer Unterrichtssprache mit bulgarischen Schulen vereinigt und damit der Unterricht in türkischer Sprache beendet. 1968 wurde zwischen der Türkei und Bulgarien eine Vereinbarung geschlossen, die vorsah, dass Familienangehörige der Emigranten von 1950-51 in die Türkei auswandern können. Infolge dieser Vereinbarung, die unter dem Namen Familienzusammenführung bekannt wurde, emigrierten über 130.000 Türken in die Türkei. ${ }^{71}$

Die größte muslimisch-türkische Auswanderung in der zweiten Hälfte des 20. Jahrhunderts fand 1989 statt. Gegen Ende 1984 und zu Beginn 1985 führte die kommunistische Regierung Bulgariens unter der Führung Todor Živkovs eine Politik der Zwangsassimilation durch, indem alle muslimisch-türkischen Personennamen mit Waffengewalt gerändert wurden. Es wurde die Behauptung aufgestellt, dass alle Muslime in Bulgarien früher Bulgaren gewesen seien und dass sie während der Osmanenzeit zwangsweise muslimisiert bzw. türkisiert worden waren. Man nannte diese Politik Wiedergeburt bzw. Rückkehr zu den Wur$z e l n$. Diese Politik und damit verbundene weitere Unterdrückungsmaßnahmen führten zur Krise in den bulgarisch-türkischen Beziehungen. Mitte 1989 akzeptierte die bulgarische Regierung die Auswanderung der Muslime und die türkische Regierung öffnete die Grenzen. Innerhalb von wenigen Monaten stieg die Zahl der Emigranten auf über 300.000 an. Daraufhin beschloss die türkische Regierung die Grenzen zu schließen und die tägliche Zahl der Emigranten, die aufgenommen wurden, zu reduzieren. Obwohl nach dem Zusammenbruch des sozialistischen Systems in Bulgarien im Jahre 1990 ein Teil dieser Emigranten zurückkehrte, blieb der größte Teil in der Türkei. ${ }^{72}$ Nach 1990 geht die Auswanderung der Türken aus sozialen und wirtschaftlichen Gründen weiter. Heute besteht die Bevölkerung Bulgariens zu 9-10 \% aus Türken/Muslimen, und trotz der EU-Mitgliedschaft Bulgariens bestehen dort weiterhin Minderheitenprobleme. Die Türken werden vor allem zur Zielscheibe der nationalistischen Bewe-

71 Crampton 2007, 199; Eminov 1997, 5-7, 99-111, 146.

72 Bojkov 2004, 343-369; Bell 1999, 237-268; Asenov 1996; Lütem 2000 und 2006. 
gungen, wie z.B. der politischen Partei Ataka, und der Diskriminierungen unter dem Vorwand der angeblichen Gefahr eines islamischen Fundamentalismus. Die allgemeinen Konflikte und Probleme bezüglich des islamischen Fundamentalismus im Nahen Osten, die mit den Muslimen in Bulgarien eigentlich nichts $\mathrm{zu}$ tun haben, werden gegen diese Minderheit gewendet. Schließlich fühlen sich die Muslime in Bulgarien weiterhin diskriminiert und bedroht, was sie im Endeffekt zu einem Potential für die Fortsetzung der Emigration in die Türkei werden lässt.

\section{Schlussbemerkungen}

Ausgehend von diesen Beispielen können wir über den Prozess der Auswanderungen in Bulgarien seit 1878 folgende Feststellungen treffen: Die muslimische Bevölkerung, die etwas weniger als die Hälfte der Gesamtbevölkerung der hier untersuchten Region Südost-Bulgarien ausmachte, und die griechische Bevölkerung, die einen wichtigen Teil der Bevölkerung im Küstengebiet bildete, wurden zum größten Teil während des osmanisch-russischen Krieges von 1877-78 und in den darauf folgenden Jahren ausgesiedelt.

Infolge dieser Auswanderungen wurde ein Viertel der muslimischen und griechischen Dörfer zu Ruinen. Ein Teil dieser entsiedelten Dörfer blieb bis heute unbesiedelt und verschwand von der Landkarte. Bei der Untersuchung der Migrationsgeschichte Bulgariens kann man meines Erachtens ohne die Berücksichtigung dieser verschwundenen Dörfer kein vollständiges Bild der demographischen Veränderungen erhalten.

Die restlichen 75\% der Dörfer wurden hauptsächlich von Bulgaren, die von Ost- und Westthrazien auswanderten, wiederbesiedelt. Nur ein kleiner Teil der muslimischen Dörfer in der Region blieben bis heute als rein muslimische oder bulgarisch-muslimisch gemischte Dörfer erhalten.

Auch die nationalstaatliche Politik der bulgarischen Regierung gegenüber der Minderheit war ein wichtiger Faktor für die Auswanderungen. Die Auswanderungen der 1930er Jahre sind ein Beispiel dafür. Aber auch die sozialistische Landwirtschaftspolitik war ein wichtiger Grund sowohl für die Auswanderung der Türken in die Türkei als auch für die innere Migration in Bulgarien. Hinzu kamen die großen infrastrukturellen Projekte, die Auswanderungen und Umsiedlungen verursachten. In dem untersuchten Gebiet spielte z.B. der Bau von Stauseen eine wichtige Rolle bei der Umsiedlung der Bevölkerung. Man muss außerdem berücksichtigen, dass seit den 1950er Jahren die Landflucht auch für Bulgarien ein wichtiges Phänomen darstellt. Die Flucht der Landbevölkerung in die Städte geht auch heute weiter. 
Zum Schluss möchte ich hervorheben, dass Migration in der modernen Balkangeschichte eine äußerst wichtige Stelle einnimmt. Um die Balkangeschichte besser zu verstehen, müssen die Migrationsprozesse berücksichtigt werden. Eine Untersuchung auf der Basis von Dörfern erweist sich als eine sehr nützliche Methode, um die Komplexität dieser Migrationsprozesse zu verstehen. Dabei ist Feldforschung natürlich unerlässlich.

\section{Literaturverzeichnis}

Adanir, Fikret, 1979: Die Makedonische Frage. Ihre Entstehung und Entwicklung bis 1908. Wiesbaden.

Ağanoğlu, H. Yıldırım, 2001: Osmanlı'dan Cumhuriyet'e Balkanlar'm Makûs Talihi Göç. Istanbul.

Asenov, Bončo, 1996: Vãzroditelnijat Proces i Dăržavna Sigurnost. Sofia.

Aydin, Mahir, 1992: Şarkî Rumeli Vilâyeti. Ankara.

Bell, John D., 1999: „,The ,Revival Process': the Turkish and Pomak Minorities in Bulgarian Politics“, in: Sfikas, Thanasis D. / Willimans, Christopher (Eds.): Ethnicity and Nationalism in East Central Europe and the Balkans. Aldershot, 237-268.

Bojkov, Victor D., 2004: „Bulgaria’s Turks in the 1980s: a Minority Endangered“, in: Journal of Genocide Research, 6 (3), 343-369.

Crampton, R. J., 2007: A Concise History of Bulgaria, (1. Auflage 1997), 2. Auflage. Cambridge.

Dayioğlu, Ali, 2005: Toplama Kampından Meclis'e Bulgaristan'da Türk ve Müslüman Azınlı̆̆ı. İstanbul.

Eminov, Ali, 1997:Turkish and Other Muslim Minorities in Bulgaria. London.

Eren, A. Cevat, 2001: „Pazvandoğlu, Osman (1758-1807)“, in: İslâm Ansiklopedisi, 9, 532-535.

Ersoy, Neriman, 1996: Bulgaristan Prensliğinde Türk Emlâki (1878-1908). Unveröffentlichte Magisterarbeit. Universität İstanbul.

Ersoy, Neriman, 2009: „Bulgaristan'da ,Müstesna Vakıflar' Sorunu ve 1909 Y1l1 Komisyon Kararları", in: Istanbul Üniversitesi Edebiyat Fakültesi Tarih Dergisi, 46/2007/2,155176.

Gülsoy, Ufuk, 1993: 1828-1829 Osmanlı-Rus Savaşı'nda Rumeli den Rusya ya Göçürülen Reâyâ. Istanbul.

Gülsoy,Ufuk, 2000: Osmanlı Gayrimüslimlerinin Askerlik Serüveni. Istanbul.

Hacısalihoğlu, Mehmet, 2003: Die Jungtürken und die Mazedonische Frage (1890-1918). München.

Hacısalihoğlu, Mehmet, 2006: „Bağımsızlıktan Günümüze Bulgaristan'da Yer İsimlerinin Değiştirilmesi“, in: Balkanlarda İslam Medeniyeti II. Milletlerarası Sempozyumu

Tebliğleri, Tiran, Arnavutluk, 4-7 Aralık 2003.(ed. Çaksu, Ali). Istanbul, 177-189. 
Hacısalihoğlu, Mehmet, 2007a: „Minorities in the Balkans and the Issue of Toponymy: the Bulgarian Case“", in: Hacısalihoğlu, Mehmet / Aksu, Fuat (Ed.): Proceedings of the International Conference on Minority Issues in the Balkans and the EU. Istanbul, 61-78.

Hacısalihoğlu, Mehmet, 2007b: „Inclusion and Exclusion: Conscription in the Ottoman Empire", in: Journal of Modern European History, V/2, 264-286.

Hacısalihoğlu, Mehmet, 2008: Doğu Rumelide Kayıp Köyler. Íslimye Sancağı'nda 1878'den Günümüze Göçler, Isim Değişiklikleri ve Harabeler. İstanbul.

Halaçoğlu, Ahmet, 1994: Balkan Harbi Sirasında Rumeliden Türk Göçleri (1912-1913). Ankara.

Heinzelmann, Tobias, 2004: Heiliger Kampf oder Landesverteidigung? Die Diskussion um die Einführung der allgemeinen Militärpflicht im Osmanischen Reich 1826-1856. Frankfurt/ Main u.a.

Hüseyin Raci Efendi: Zağra Müftüsünün Hatıraları. Tarihçe-i Vak’a-i Zağra, Druckvorbereitung durch Ertuğrul Düzdağ, ohne Ort und ohne Datum (Serie der Zeitung Tercüman 1001 Temel Eser 24).

İpek, Nedim, 1994: Rumeli'den Anadolu'ya Türk Göçleri (1877-1890). Ankara.

İpek, Nedim, 2006: Imparatorluktan Ulus Devlete Göçler. Trabzon.

Kerman, Zeynep, 1987: Haziran-Temmuz ve Ağustos 1877 Ruslar'in Asya'da ve Rumeli'de Yaptıkları Mezâlim. İstanbul.

Kocacik, Faruk, 1980: „Balkanlar'dan Anadolu’ya Yönelik Göçler (1878-1890)“, in: Osmanlı Araştırmaları, I, 137-190.

Lütem, Ömer E., 2000 und 2006: Türk-Bulgar İlşskileri 1983-1989, Bd. I: 1983-1985, Bd. II: 1986-1987. Ankara.

Mičev, Nikolay / Koledarov, Petăr, 1989: Rečnik na Selištata i Selištnite Imena v Bălgarija, 1878-1987. Sofia (Erste Auflage: Promenite v Imena i Statuta na Selištata v Bălgarija, 1878-1972 g. Sofia 1973).

Mitev, Yono, 1980: The Struggle of the Bulgarians for a United State and Against the Decisions of the Berlin Congress of 1878. Sofya.

Moltke, Baron von, 1932: 1828 Seferi: Bulgarya ve Rumeli de Ruslar, (ins Türkische übersetzt von Ahmed Rasim, Muammer). Istanbul.

Mutafčieva, Vera, 1977: Kărdžalijsko Vreme. Sofia.

Önder, Selahattin, 1991: „Meclis-i Vükela Mazbatalarında Türk-Bulgar Mübadelesi“, in: Anadolu Üniversitesi Fen-Edebiyat Fakültesi Dergisi, III/1, 207-225.

Österreichische Heereskarte (ÖHK),1913: Generalkarte von Mitteleuropa, 1: 200.000 m., Vorb. K.u.K. Militärgeographisches Institut Wien, 1913-1915, Neudruck 19391940 .

Osmanische Heereskarte (OHK), 1900: Rum ili-i Şahane Haritası. 1: 210.000 m., Haz. Erkan-i Harbiye istiksaf postalarin tarafindan ..., tarih 1317 (1899-1900).

Radova, O. K., 2006: „Preselenčeskoe Dviženie v XVIII-Pervoj Polovine XIX vv. Osnovnye ètapy i ich osobennosti“, in: Istorija i kultura Gaguzov. Komrat-Kišineu, 71-88. 
Russische Heereskarte (RHK),1884: Karty Casti Balkanskago Poluostrova, 1: 126.000 verst. vorbereitet vom Russischen Generalstab, Militärisches Topographie-Department, 1884, wiedergedruckt 1895. (Vorbereitet von: Sidorov, Butovič, Maležev und Ivanov).

Salname Edirne, 1290: Salname 1290 [1873], Defa 4.

Şimşir, Bilâl N., 1989: Rumeli’den Türk Göçleri. Belgeler, Bd. I: Doksanüç Muhacereti 18771878, Bd. II: Bir Geçiş Yilı 1879, Bd. III: 1880-1885. Ankara.

Şimşir, Bilâl N., 1992: „Bulgaristan Türkleri ve Göç Sorunu“, in: Bulgaristan'da Türk Varlığı. Bildiriler, 7 Haziran 1985, 3. Auflage. Ankara, 47-66.

Spisăk na Naselenite Mesta v Tsarstvo Bălgariya ot Osvoboždenieto (1879) do 1910 Godina / Liste des Localites dans le Royaume de Bulgarie depuis la Liberataion (1879) jusqu'en 1910. Sofia 1921.

Stojanov, Valeri,1998: Turskoto Naselenie v Bălgarija mežzu poljusite na etničeskata politika. Sofia.

Tabakov, Simeon, 2002: Opit za Istorija na Grad Sliven, Bd. II, 2. Auflage. Sofia.

Vraçali, Sofroni, 2003: Osmanlı'da Bir Papaz. Günahkâr Sofroni'nin Çileli Hayat Hikâyesi, (ins Türkische übersetzt von Aziz N. Ş. Taş). İstanbul.

Zürcher, Erik Jan, 1998: „The Ottoman Conscription System, 1844-1914“, in: International Review of Social History, 43, 437-449 (für denselben Artikel s. auch: Arming the State: Military Conscription in the Middle East and Central Asia, 1775-1925, Ed. Erik Jan Zürcher, London, New York 1999, 79-94). 